\title{
OPEM
}

www.opem.org

Oriental Pharmacy and Experimental Medicine 2008 8(4), 380-385

DOI 10.3742/OPEM.2008.8.4.380

\section{Immunomodulatory effect of Tinospora cordifolia and Centella asiatica and its modulation on cyclophosphamide challenge}

\author{
NA Siddiqui ${ }^{1, *}$, Mohd Ali ${ }^{2}$ and Shobhna Singh ${ }^{3}$ \\ ${ }^{I}$ Department of Pharmacy, I.E.T., M.J.P.Rohilkhand University, Bareilly (U.P.), India; ${ }^{2}$ Department of Pharmacognosy \& \\ Phytochemistry, Faculty of Pharmacy, Jamia Hamdard, New Delhi, India; ${ }^{3}$ Department of Pharmacy, I.E.T., \\ M.J.P.Rohilkhand University, Bareilly (U.P.), India
}

Received for publication September 10, 2007; accepted March 18, 2008

\begin{abstract}
SUMMARY
Ethanolic extracts of T. cordifolia and C. asiatica were evaluated for immunostimulatory effect in mice against sheep RBCs as antigen by three models viz. delayed type hypersensitivity reaction, percent change in neutrophil count and haemagglutination titre. Immunostimulatory effect in the presence of immunosuppressant agent, cyclophosphamide $(100 \mathrm{mg} / \mathrm{kg}$, i.p.) was also investigated. T. cordifolia and C. asiatica significantly $(p<0.001, p<0.05$ respectively) enhanced foot pad thickness when measured after 24 hours of sheep RBC antigen challenge. Both the plant materials increased foot pad thickness even after being subjected to immunosuppressant exposure. T. cordifolia revealed enhanced neutrophil counts, while C. asiatica had no significant effect on neutrophil counts. T. cordifolia exhibited significantly $(P<0.01)$ elevated neutrophil levels even in the presence of cyclophosphamide administration. Both the plants exhibited humoral antibody response, as haemagglutination titre values were significantly high as compared to control. T. cordifolia and $C$. asiatica could combat immunosuppressant effect of cyclophosphamide $(P<0.01)$. This suggests that $T$. cordifolia and $C$. asiatica can be regarded as biological response modifiers and can be utilized for the development of immunostimulating agent among plant sources.
\end{abstract}

Key words: Immunomodulation; Neutrophils; Haemagglutination titre; Cyclophosphamide

\section{INTRODUCTION}

From time immemorial, plants have been explored as medicines by human beings and insurgence to plant based products has increased. Plant products, in the form of whole extracts, have become increasingly respectable for consumers as well as physicians. Some of the medicinal plants are believed

\footnotetext{
*Correspondence: NA Siddiqui, Department of Pharmacy, I.E.T., M.J.P.Rohilkhand University, Bareilly (U.P.), India. Tel: +0091-9456244935, 0091-581-2315192; E-mail: nasirpharm@yahoo.co.in
}

to promote positive health and maintain organic resistance against infection by re-establishing body equilibrium and conditioning of the body tissues (Bhagwan, 1978). T. cordifolia has been reported to enhance host resistance and reduce side effects of some toxic agents (Dhuley, 1997). Methanolic extract of stem of $T$. cordifolia has been reported to increase WBCs and it increased bone marrow cellularity. This extract also increased plaque forming cells in the spleen, circulating antibody titre and increased the macrophage activation (Mathew and Kuttan, 1999). The aqueous and 
ethanolic extract of $T$. cordifolia inhibited the immunosupression produced by cyclophosphamide (Manjrekar et al., 2000). While C. asiatica have been proved to be useful strong adaptogenic agent. It has been included in the formulation of herbal preparations, CIHP I and II, which are adaptogenic preparations (Grover et al., 1995).

The restorative and rejuvenating power of these plants might be due to their action on immune system, which is responsible for the protection against various diseases. Looking into the beneficial effects of drug extracts and their herbal formulations, the present study is an attempt to explore the immunomodulatory effects of T. cordifolia and $C$. asiatica against sheep RBC antigen challenge in mice via three models viz. delayed type hyper sensitivity reaction, neutrophil count, and humoral antibody response in mice. Immunostimulant activity in the presence of immunosuppressant, cyclophosphamide has also been investigated.

\section{MATERIALS AND METHODS}

\section{Plant materials and chemicals}

The dried aerial parts of $C$. asiatica commonly known as 'Brahmi' and stem cuttings of T. cordifolia commonly known as 'Giloya' were purchased from "Natural Drugs and Botanicals", Sahibabad, Ghaziabad (U.P.) and identified by a taxonomist. A voucher specimen of all the crude drugs has been deposited in the "Phytochemistry Research Laboratory", Faculty of Pharmacy, Jamia Hamdard, New Delhi.

Cyclophosphamide (Ledoxan) was purchased from Dabur India Ltd., Ghaziabad, (U.P.), India and used as an immunosuppressant. For dosing, the drug was dissolved in water for injection i.p.

Carboxy methyl cellulose (CMC) and sodium chloride were purchased from s.d. fine Chemicals Ltd, Mumbai, India.

\section{Extract Preparation}

The air dried drug was coarsely powdered and exhaustively extracted in a Soxhlet apparatus with ethanol (95\%) for $72 \mathrm{~h}$. The extract was concentrated and dried on rotary flash evaporator to get a dark brown mass. The dried extract was used for the pharmacological investigations.

\section{Animals}

Swiss albino mice of either sex, weighing $20-25 \mathrm{~g}$, were housed in standard conditions of temperature, humidity, $12 \mathrm{~h} / 12 \mathrm{~h}$ light/dark cycles and fed with standard pellet diet (Hindustan Lever Pellets, Bangalore, India) and tap water ad libitum. The animals were obtained from the Laboratory Animal Resource Section, Division of Animal Genetics, Indian Veterinary Research Institute, Izat Nagar, Bareilly (U.P.), India and experimentation was carried out with prior approval of the ethical Committee for the Purpose of Control and Supervision of Experiments on Animals (CPCSEA), vide approval number 453/01/a/CPCSEA.

\section{Antigen}

Sheep red blood cells (SRBC) were obtained from Division of Pathology, Indian Veterinary Research Institute, Izat Nagar, Bareilly (U.P.), collected in Alsevier's solution and washed three times in large volumes of pyrogen-free, sterile saline and adjusted to a concentration of $0.1 \mathrm{ml}$ containing $1 \times 10^{8}$ cells.

\section{Methodology}

The $95 \%$ ethanolic extracts of T. cordifolia and C. asiatica were administered as $0.1 \%$ suspension of CMC intraperitoneally at a dose of $100 \mathrm{mg} / \mathrm{kg}$ body weight/day, from day 1 to day 14 .

Cyclophosphamide was dissolved in water for injection i.p. and injected at a dose of $100 \mathrm{mg} / \mathrm{kg}$ body weight, i.p. on day 12 to the animals of group IA, IIA and IIIA. Sheep RBCs were adjusted to a concentration of $0.1 \mathrm{ml}$ containing $1 \times 10^{8}$ cells administered intraperitoneally on day 7 as sensitizing dose and $0.05 \mathrm{ml}$ (containing $2 \times 10^{8}$ cells) on day 14 as challenging dose given subcutaneously in right hind foot paw in all groups. 


\section{Delayed Type Hypersensitivity (DTH) Reaction}

The method described by Doherty (1981) was used in the present study. Mice of either sex were divided into six groups of six each. The mice of all groups were primed with $0.1 \mathrm{ml}$ of SRBC suspension containing $1 \times 10^{8}$ cells, i.p., on day 7 and challenged on day 14 with $0.05 \mathrm{ml}$ of $2 \times 10^{8}$ $\mathrm{SRBC}$ in the right hind foot pad. The contralateral paw received equal volume of saline. During this period, the ethanolic extracts of test drugs were fed from day 1 to day 14 in the dose $100 \mathrm{mg} / \mathrm{kg}$ body weight, i.p. to the animals of group II, III, IIA and IIIA while the animals of control groups I and IA received $0.1 \% \mathrm{CMC}$ intraperitoneally. On day 12 , one group for each test drug (group IIA and IIIA) and a control group (group IA) were administered with cyclophosphamide $(100 \mathrm{mg} / \mathrm{kg}$ body weight, i.p.). On day 14 , the thickness of the foot pads of all the groups was measured at 24 and $48 \mathrm{~h}$ after challenging. It was measured by plethysmometer (Ugo Basil, Italy). The difference in the thickness of the right hind paw and the left hind paw was used as a measure of delayed type hypersensitivity (DTH) reaction.

\section{Neutrophil Count}

The method for neutrophil count was described by Ziauddin et al. (1996). Mice of either sex were divided into six groups of six each. The treatment schedule was similar to that of SRBC-induced DTH reaction. After sensitization with SRBC on day 7 , blood samples were collected from the retro-orbital plexus of individual animals on day 10 and then on day 14 in all the groups. The differential leukocyte count was performed by fixing the blood smears and staining with Field Stains A and B, and percent neutrophil in each sample was determined.

\section{Humoral Antibody (HA) Response}

Mice of either sex were divided into six groups of six each. The treatment schedule was similar to that of SRBC-induced DTH reaction. After sensitization with SRBC on day 7, blood samples were collected from the retro-orbital plexus of individual animals on day 10 and then on day 14 in all groups. The antibody titres were determined using the method described by Puri et al. (1994). Briefly, an aliquot $(25 \mu \mathrm{l})$ of two fold diluted sera in saline was challenged with $25 \mu \mathrm{l}$ of $0.1 \% \mathrm{v} / \mathrm{v}$ SRBC suspension in microtitreplates (Laxbro). The plates were incubated at $37^{\circ} \mathrm{C}$ for $1 \mathrm{~h}$ and then observed for haemagglutination. The highest dilution giving haemagglutination was taken as the antibody titre. The antibody titres were expressed in a graded manner, the minimum dilution may be represented as $1 / 2$. The mean dilutions of different groups were statistically compared.

\section{Statistical analysis}

Data were expressed as the mean \pm standard error of the mean (S.E.M.) and statistical analysis was carried out by employing one- analysis of variance (ANOVA) followed by Dunnett's test. $P<0.05$ was considered to be statistically significant.

\section{RESULTS}

The effect of both the plant material T. cordifolia and C. asiatica on experimentally induced DTH reaction has been shown in table. Both the plant materials significantly enhanced the foot pad thickness when measured after $24 \mathrm{~h}$ of challenge. The foot pad thickness normalized within forty eight hours in both the groups. Thus the results of DTH study indicate that the ethanolic extracts of both the plant materials function as mediators of ensuring hypersensitivity response particularly by attracting and activating macrophages. Cyclophosphamide challenge decreased delayed type hypersensitivity reaction in mice as compared to the control group without cyclophosphamide treatment (group I Vs group IA). Pretreatment with T. cordifolia and $C$. asiatica could combat the immunosuppressant effect of cyclophosphamide as in both the groups IIA and IIIA, there was significant increase in foot pad thickness after $24 \mathrm{~h}$ of day 14 challenge by 
Table 1. Immunological activity profiles of ethanolic extract of T. cordifolia and C. asiatica against sheep RBCs in presence and absence of cyclophosphamide

\begin{tabular}{|c|c|c|c|c|c|}
\hline \multirow{2}{*}{ Groups } & \multirow{2}{*}{ Treatment } & \multicolumn{2}{|c|}{ DTH Activity } & \multirow{2}{*}{$\begin{array}{l}\text { Neutrophil } \\
\text { counts (\%) }\end{array}$} & \multirow{2}{*}{ HA Titre } \\
\hline & & $24 \mathrm{~h}$ & $48 \mathrm{~h}$ & & \\
\hline$\overline{\mathrm{I}}$ & Control (0.1\% CMC) & $0.28 \pm 0.01$ & $0.20 \pm 0.01$ & $70 \pm 0.58$ & $16.33 \pm 0.33$ \\
\hline II & T. cordifolia & $0.37 \pm 0.01^{* * *}$ & $0.18 \pm 0.01$ & $78 \pm 1.07^{* *}$ & $117.33 \pm 10.67^{* *}$ \\
\hline III & C. asiatica & $0.30 \pm 0.01^{*}$ & $0.21 \pm 0.01$ & $68 \pm 1.65$ & $58.67 \pm 5.33^{*}$ \\
\hline I A & Control $(0.1 \% \mathrm{CMC}+\mathrm{CP})$ & $0.16 \pm 0.01$ & $0.25 \pm 0.13$ & $55 \pm 1.65$ & $14.67 \pm 4.34$ \\
\hline II A & T. cordifolia $+\mathrm{CP}$ & $0.21 \pm 0.01^{* *}$ & $0.14 \pm 0.01$ & $63 \pm 0.73^{* *}$ & $29.33 \pm 2.67^{* *}$ \\
\hline III A & C. asiatica + CP & $0.21 \pm 0.01^{* * *}$ & $0.13 \pm 0.01$ & $54 \pm 1.27$ & $29.33 \pm 2.67^{* *}$ \\
\hline
\end{tabular}

$\mathrm{N}=6$ mice per group, tabular value represents mean \pm S.E., dose: $100 \mathrm{mg} / \mathrm{kg}$, for all the substances. ${ }^{*} P<0.05$; ${ }^{* *} P<0.01 ;{ }^{* * *} P<0.001$.

SRBC. The foot pad thickness normalized within $48 \mathrm{~h}$ of challenge in the animals of all groups.

Blood was collected on day 1 and analysed for percent neutrophil count. The animals were sensitized with sheep RBC on day 07, blood samples were collected from retro-orbital plexus of each animal on day 10 and day 14, and percent neutrophil count was made for each sample. The percent neutrophil count on day 10 was found to be slightly more as compared to day $01(\mathrm{P}=\mathrm{NS})$ in all groups. The count of day 14 was found to be significantly enhanced by $T$. cordifolia $(P<0.01)$. The neutrophil count remained unchanged in $C$. asiatica treated group. Thus $T$. cordifolia significantly augmented neutrophil count while C. asiatica had no effect on the same. Cyclophosphamide administration caused reduction in neutrophil counts in control group IA, as compared to control group I. Pretreatment with T. cordifolia significantly $(P<0.01)$ enhanced the neutrophil count as compared to control group IA ( $0.1 \% \mathrm{CMC}+$ Cyclophosphamide) even in the presence of cyclophosphamide. Ethanolic extract of C. asiatica had no significant effect on neutrophil count in cyclophosphamide treated group.

After sensitization with $0.1 \mathrm{ml}\left(1 \times 10^{8}\right)$ sheep R.B.C. on day 07, the blood samples were taken from retro- orbital plexus from each animal on day 10 and day 14 . The antibody titre was determined for all groups, utilising the blood sample collected. After 10 days of treatment by the test materials i.e. extract of T. cordifolia and C. asiatica, the results reveal no change in haemagglutination (group II and III). However the samples of day 14 exhibited significant humoral antibody response. Increased HA titre values in the T. cordifolia and C. asiatica treated groups showed significant humoral antibody response as compared to control group I $(P<0.01$. $P<0.05$ respectively). The myelosuppressant effect of cyclophosphamide has been revealed by the observance of slight decrease in HA titre value in group IA as compared to control group I. The HA titre value in cyclophosphamide treated groups reveals that $T$. cordifolia and $C$. asiatica treatment could combat the myelosupressant effect of cyclophosphamide $(P<0.01)$ as they showed increased HA titre value as compared to control group IA.

\section{DISCUSSION}

Delayed type hypersensitivity reaction is characterized by large influxes of non specific inflammatory cells in which macrophage are a major participant. It is a type IV hypersensitivity reaction that develops when antigen activates sensitized $\mathrm{T}_{\text {DTH }}$ cells. Activation of $\mathrm{T}_{\mathrm{DTH}}$ cells in the presence of the antigen through appropriate antigen action leads to secretion of various cytokines including interlukin-2, interferon- $\gamma$, macrophage migration inhibition factor and tumor necrosis factor- $\beta$ (Askenase and Van Loveren, 1983). Secreted 
cytokines recruit macrophages into the area and activate them, promoting enhanced phagocytic activity, vis-a-vis augmented concentration of lytic enzymes for more effective killing of foreign entities. Thus DTH reaction is important in host defense against parasite and bacteria that can live and proliferate within the cells. In the present study, T. cordifolia and C. asiatica showed significant increase in foot pad thickness when measured after $24 \mathrm{~h}$ of sheep RBC challenge. The foot pad thickness normalized within $48 \mathrm{~h}$. Administration of cyclophosphamide in animal reduced mean foot pad thickness in control group IA as compared to control without cyclophosphamide exposure. Both the drugs significantly enhanced the foot pad thickness even in the presence of cyclophosphamide, which reveals that the test materials have effect on T-cells and may play a role in providing immunity against parasite and bacterial intracellular proliferation.

The role of phagocytosis is primarily the removal of micro-organisms and foreign bodies, and also the elimination of dead or injured cells. Phagocytic defects are associated with varied pathological conditions in humans. Neutrophils are capable of phagocytosis and their enhancement may provide immunity through phagocytosis. In view of the pivotal role played by neutrophils the test extracts were evaluated for their effect on neutrophil counts. Pretreatment of mice with the extract of T. cordifolia enhanced total neutrophil count significantly $(P<0.01)$ when sensitized with antigen, sheep RBCs. The neutrophil levels decreased in the presence of immunosuppressant agent, cyclophosphamide in the control group IA as compared to control group I. Extract of $T$. cordifolia increased neutrophil count even in the presence of immunosuppressant cyclophophamide $(P<0.01)$ hence $T$. cordifolia may be useful in promoting the protection of body by phagocytosis, even in diseased conditions where immunity is depressed. C. asiatica revealed no significant effect on neutrophil count. However, the levels remain within the normal range of mice.
T. cordifolia was found to be more effective $(P<$ $0.01)$ than $C$. asiatica $(P<0.05)$ for HA titre activity. Both the plants enhanced the antibody production even when animals were exposed to immunosuppressant treatment with cyclophosphamide thus both the drugs could combat the myelosupressant effect of cyclophosphamide. The present study establishes the immunostimulant status of T. cordifolia and C. asiatica as both of them played a role in the activation of T-lymphocytes and the augmentation of circulating antibodies. $T$. cordifolia was found to be more beneficial in terms of immunostimulant effect as it could enhance neutrophil count in the presence as well as in the absence of cyclophosphamide. Authors have also reported immunomodulatory effect of T. cordifolia's polysaccharide on natural killer cells, T-cells and Bcells in the dose $100 \mu \mathrm{g} / \mathrm{ml}$ (Nair et al., 2004). Thus, the results indicate that $T$. cordifolia is a promising immunostimulatory agent as per designed models of immunostimulatory activity. It influenced T-cells production, enhanced neutrophil counts and produced significant humoral response against sheep RBCs in the absence as well as in the presence of immunosuppressing agent, cyclophosphamide. $C$. asiatica was next to T. cordifolia as an immunostimulating agent as it could enhance phagocytosis by T-cells and have good humoral response in the presence as well as in the absence of cyclophosphamide but had no effect on neutrophil count. The immunostimulant properties of $C$. asiatica have been reported to be comparable to recombinant interferon $\alpha-2 b$ injection (Patil et al., 1998). Authors have reported its immunomodulating activity due to non specific cellular and humoral immune responses. The data available till date, suggest that it may have chemopreventive or anticancer potential (Punturee et al., 2005). Further in depth study on the parameters investigated in the present experimentation, need to be designed and explored for immunomodulatory activity. Both the test materials can further be utilized for development of immunostimulant agents against various diseases 
because T. cordifolia and C. asiatica extracts have been found to have influenced several different functions of immune system.

The findings of the present study establish the immunostimulant status of the drugs $T$. cordifolia and $C$. asiatica and suggest their therapeutic usefulness in a variety of diseases susceptible to immunomodulation.

\section{ACKNOWLEDGEMENTS}

The authors are grateful to the Laboratory Animal Resource Section, Division of Animal Genetics, Indian Veterinary Research Institute, Izat Nagar, Bareilly, India for providing the animals and facilities for pharmacological activity. We are also thankful to "Natural drugs and Botanicals" Sahibabad, Ghaziabad (U.P.), India for supplying genuine plant materials.

\section{REFERENCES}

Askenase PW, Van Loveren M. (1983) Delayed type hypersensitivity: activation of mast cells by antigen specific T-cell factors initiates cascade of cellular interactions. Immunology Today 4, 259-264.

Bhagwan Dash V. (1978) Fundamentals of Ayurvedic Medicine, Bansal and Company, Delhi, India, ix-xvi.

Dhuley JN. (1997) Effects of some Indian herbs on macrophage functions in Ochratoxin A treated mice. J. Ethnopharmacol. 58, 15-20.

Doherty NS. (1981) Selective effects of immunosuppressive agents against the delayed type hypersensitivity response and humoral response to sheep red blood cells in mice. Ag. Actions 11, 237-242.

Grover SK, Divekar HM, Kumar R, Palwa ML, Bhardwaj SK, Gupta AK, Srivastava KK. (1995) Experimental evaluation of a Composite Indian Herbal Preparation II (CIHP II) as an adaptogen and its mechanism of action. Int. J. Pharmacog. 33, 148-154.

Manjrekar PN, Jolly CI, Narayan S. (2000) Comparative studies of the immunomodulatory activity of Tinospora cordifolia and Tinospora sinensis. Fitoterapia 41, 254-257.

Mathew S, Kuttan G. (1999) Immunomodulatory and antitumour activities of Tinospora cordifolia. Fitoterapia 70, 35-43.

Nair PK, Rodriguez S, Ramachandran R, Alamo A, Melnick SJ, Escalon E, Garcia PI Jr, Wnuk SF, Ramachandram C. (2004) Immunostimulating properties of a novel polysaccharide from the medicinal plant Tinospora cordifolia. Int. J. Immunopharmacol. 15, 1645-1659.

Patil TS, Nagavi BG, Ramesh M, Vijayakumar GS. (1998) A study on the immunostimulant activity of Centella asiatica Linn. in rats. Indian Drugs 35, 711714.

Punturee K, Wild CP, Kasinrerk W, Vinitketkumneun U. (2005) Immunomodulatory activities of Centella asiatica and Rhinacanthus nasutus extracts. Asian Pac. J. Cancer Prev. 6, 396-400.

Puri A, Saxena R, Saxena KC, Tandon JS. (1994) Immunostimulant activity of Nyctanthes arbortritis L. J. Ethanopharmacol. 42, 31-37.

Ziauddin M, Phansalkar N, Patki P, Diwanay S, Patwardhan B. (1996). Studies on the immunomodulatory effects of ashwagandha. J. Ethnopharmacol. 50, 69-76. 